\title{
Practice What We Teach
}

Most of us hold opinions on contemporary issues in work practice, in all its broad dimensions. Sounding Board is a regular feature of this publication, designed to provide a forum for expressing such views, whether mainstream or controversial.

The opinions expressed in this section may not be necessarily represent the views of the editor, the publisher, or the editorial board, but are intended to stimulate discussion or to provoke a response. Readers who wish to comment on the ideas put forth in Sounding Board should address their comments to the editor.

Terri J. Pickett, OTR/L

El Paso, Texas

Therapists are users of ergonomic principles in every type of clinical setting and in each treatment session. The environment is adjusted to meet the needs of the client to allow the individual to achieve optimum success. Assessment and adjustments can be made fairly quickly to meet the client's needs. If we believe these principles help to achieve optimum success and work efficiency, then why do therapists' own workstations not reflect these beliefs?

The workstation is a place for completing documentation and storing information. The amount and type of paperwork varies with each staff position and associated responsibilities. Throughout the day, observe where therapists escape to complete documentation. They will go to areas that have low noise level, minimal distractions, quality lighting, and enough usable work space for writing and keeping paperwork organized. Consider the aforementioned factors when assessing the workstations along with height of workstation, adjustable seating height, and environmental temperature. Also consider mental load, for at this workstation, multiple tasks are performed simultaneously. A high level of concentration is maintained, the demands of information handling must be met, complex decisions are made, and daily stresses are managed.

Realizing that there are financial limitations in making adjustments at workstations and that this is an administrative decision, it is of primary importance to show the need for such changes and the resulting benefits. One of those benefits is in the hiring and retention of therapists. Providing optimal work space is not only an additional recruiting point, but it sends the message that there is concern for the welfare and retention of current employees.

Given rehabilitation professionals' strong belief in providing quality care, do we believe strongly enough in these principles to care for the caregivers? 